Société d'histoire de la révolution de 1848 et des révolutions du XIXe siècle

$37 \mid 2008$

L'ère victorienne revisitée

Index général de la correspondance de Flaubert, éditée par Jean Bruneau et Yvan Leclerc/Direction des ARCHIVES DE FRANCE, Guide des sources de la Commune de Paris et du mouvement communaliste (1864-1880). Paris et Île-de-France

Jean-Claude Caron

\title{
OpenEdition
}

Journals

Édition électronique

URL : http://journals.openedition.org/rh19/3532

DOI : $10.4000 /$ rh 19.3532

ISSN : $1777-5329$

Éditeur

La Société de 1848

Édition imprimée

Date de publication : 15 novembre 2008

Pagination : 185-242

ISSN : 1265-1354

Référence électronique

Jean-Claude Caron, «Index général de la correspondance de Flaubert, éditée par Jean Bruneau et Yvan Leclerc/Direction des ARCHIVES DE FRANCE, Guide des sources de la Commune de Paris et du mouvement communaliste (1864-1880). Paris et Île-de-France », Revue d'histoire du XIXe siècle [En ligne], 37 | 2008, mis en ligne le 01 décembre 2008, consulté le 22 septembre 2020. URL : http:// journals.openedition.org/rh19/3532 ; DOI : https://doi.org/10.4000/rh19.3532

Ce document a été généré automatiquement le 22 septembre 2020

Tous droits réservés 


\section{Index général de la correspondance de Flaubert, éditée par Jean Bruneau et Yvan Leclerc/Direction des ARCHIVES DE FRANCE, Guide des sources de la Commune de Paris et du mouvement communaliste (1864-1880). Paris et Île-de-France}

Jean-Claude Caron

\section{RÉFÉRENCE}

Index général de la correspondance de Flaubert, éditée par Jean Bruneau et Yvan Leclerc, index par Jean-Benoît Guinot, avec la collaboration de Matthieu Desportes, Marie-Paule Dupuy, Maurice Gasnier, Jean-Paul Levasseur et Christoph Oberlé, Paris, NRF-Gallimard, 2007, Bibliothèque de la Pléiade, 484 p. ISBN : 978-2-07-011932-5.

15 euros.

Direction des ARCHIVES DE FRANCE,Guide des sources de la Commune de Paris et du mouvement communaliste (1864-1880). Paris et île-de-France, établi par l'Association des amis de la Commune de Paris-1871 avec le concours des services d'archives publics et le soutien de la Ville de Paris, Paris, La documentation française, 2007, 731 p. ISBN : 978-2-11-006548-3. 65 euros.

Nous ne faisons ici que signaler, plutôt que recenser, ces volumes publiés en 2007. Ces deux ouvrages relèvent de ce qu'on pourrait qualifier, sans aucun esprit péjoratif, des outils de travail. Ils sont tous deux remarquables et, plutôt que chercher ce qui les 
réunit (et qui n'est pas vain : le mouvement communaliste, la Commune de Paris et ses principaux acteurs sont bel et bien présents dans la correspondance de Flaubert), il convient de préciser leur objet particulier.

2 L'Index coïncide avec l'achèvement de la publication des cinq tomes de la correspondance de Flaubert. Tout historien du XIX ${ }^{e}$ siècle connaît la richesse de cette correspondance qui couvre la totalité de la vie du romancier. Une œuvre dans l'œuvre, à l'instar de celle d'un Michelet ou d'une George Sand, tous deux présents dans cet Index (surtout la seconde, correspondante privilégiée de Flaubert, comme on le sait). L'intelligence des auteurs de ce volume est d'avoir conçu un travail prenant en compte les noms de personnes, contemporaines ou non, et ceux de lieux, mais encore les noms de revues ou de journaux, les titres de roman, les événements historiques ou politiques (ainsi des révolutions de 1789, de 1830, de 1848). De plus, les notices ne sont pas seulement informatives, mais ont une vocation descriptive : chaque occurrence relevée est accompagnée d'un court mais significatif résumé de la citation repérée. Deux exemples à l'appui : «Dieu » est l'objet de deux pages de références, parmi lesquelles celle-ci trouvée dans le premier tome de la Correspondance et résumée ainsi : "La quantité de crétins dont le Bon Dieu a parsemé la terre est incroyable »- du Flaubert dans le texte... Citation qu'on rapprochera de celle donnée à « Être suprême » : « On a eu raison de reprocher l'Être suprême à ce calotin de Robespierre » (V, 740). Le second exemple est révélateur des perspectives ouvertes par cet Index : les pages 320 à 337 sont consacrées à Paris et aux Parisiens et offrent à qui veut s'en saisir une géographie parisienne par quartier, par rue, par lieu de toute nature. Une véritable vie parisienne permettant de suivre la sociabilité flaubertienne depuis ses années d'apprentissage jusqu'à celles de la vieillesse. Ces deux exemples ne résument pas cet outil, ils en donnent l'esprit et en signalent l'importance. Ajoutons que cet Index est vendu séparément des cinq volumes de la correspondance, à un prix abordable (15 euros).

3 Le Guide des sources de la Commune de Paris comble un vide évident - tout aussi que celui, non comblé encore, des sources de la Révolution de 1848 et de la Seconde République. Les dimensions de ce volume disent son ambition : fournir un répertoire aussi complet que possible des sources disponibles à Paris et dans la région Île-de-France - un ensemble correspondant aux anciens départements de la Seine, de la Seine-et-Marne et de la Seine-et-Oise. On ne parlera pas ici de surprises ou de révélations inattendues, mais cet outil de travail est d'autant plus précieux qu'il fournit, outre les séries publiques des archives nationales, de très précieuses rubriques sur les archives privées des archives nationales, sur les archives départementales et sur les archives communales. Là aussi, le contenu n'est pas qu'informatif. Des descriptions précises sont parfois fournies, en particulier sur des individus. Soit l'exemple des dossiers de procédure du Tribunal correctionnel de la Seine : sur 22 pages sont donnés les noms, les motifs et la date d'inculpation, la cote du dossier. Pour autant, cette liste n'est pas exhaustive, dans la mesure où, précise le Guide, « nous n'avons indiqué que les dossiers concernant directement ou indirectement la Commune, écartant ceux qui relèvent clairement du droit commun» (p.287). Ce Guide se distingue par son ampleur chronologique. C'est depuis l'Empire libéral et jusqu'à la loi d'amnistie que l'on peut suivre le mouvement communaliste. Au delà, le regroupement des sources communales en grandes périodes permet parfois de suivre (ainsi à Champs-sur-Marne) la vie politique depuis les plébiscites de 1851 et 1852 . On remarque également la place importante de la guerre franco-prussienne de 1870-1871 dans les archives des 
communes de la banlieue parisienne. On trouvera enfin de nombreuses rubriques consacrées aux fonds iconographiques conservés dans des institutions archivistiques ou muséales. 